\title{
Controles internos e a sua eficiência ou ineficiência no processo tributário aplicado ao setor varejista de cosméticos e perfumaria: um estudo teórico empírico
}

Este estudo analisou os riscos possíveis no processo de apuração das contribuições do PIS/Pasep e da Cofins no setor de cosméticos e perfumaria aplicado ao comércio varejista, observando se os controles internos existentes são suficientes para garantir a eficiência tributária em cada empresa. A metodologia usada neste trabalho foi de aplicação de questionário sobre o processo de tributação incidente sobre as vendas em lojas de varejo do ramo de perfumaria e cosméticos de um shopping na capital do estado de Santa Catariana. Essa pesquisa ficou limitada a produtos de tributação diferenciada, conhecida como tributação monofásica aplicada as contribuições conhecidas como PIS/PASEP e COFINS. A investigação focou-se em demonstrar a relação entre os controles internos e a apuração desses tributos, a responsabilidade compartilhada dos profissionais da área contábil e administrativa e a importância de haver conhecimento para que não haja tributação desnecessária, os resultados revelaram um índice considerável de uma probabilidade de ineficiência do processo tributário, onde as informações existentes e trabalhadas para o processo tributário não são suficientes para a publicação correta de uma redução tributária possível para esse setor. Além disso, essa condição revela um cenário interessante, pois apesar de um cenário burocrático e custoso, considerado o setor tributário. Diante disso, essa pesquisa revela-se a probabilidade de uma ineficiência considerável no setor tributário.

\section{Internal controls and their efficiency or inefficiency in the tax process applied to the cosmetics and perfumery retail sector: an empirical theoretical study}

This study analyzed the possible risks in the process of calculating the contributions of PIS/Pasep and Cofins in the cosmetics and perfumery sector applied to retail trade, observing whether the existing internal controls are sufficient to guarantee tax efficiency in each company. The methodology used in this work was to apply a questionnaire on the taxation process on sales in retail stores in the perfumery and cosmetics sector of a mall in the capital of the state of Santa Catariana. This research was limited to differentiated taxation products, known as single-phase taxation, applied to contributions known as PIS/PASEP and COFINS. The investigation focused on demonstrating the relationship between internal controls and the calculation of these taxes, the shared responsibility of accounting and administrative professionals and the importance of having knowledge so that there is no unnecessary taxation, the results revealed a considerable index of one probability of inefficiency of the tax process, where the existing and worked information for the tax process is not sufficient for the correct publication of a possible tax reduction for this sector. In addition, this condition reveals an interesting scenario, because despite a bureaucratic and costly scenario, considered the tax sector. In light of this, this research reveals the probability of considerable inefficiency in the tax sector.

Keywords: Internal Controls; PIS/Pasep; Cofins.

Topic: Contabilidade Fiscal e Tributária

Reviewed anonymously in the process of blind peer
Received: 10/10/2020

Approved: 21/12/2020
Ana Paula Haskel (ii)

Universidade Federal de Santa Catarina, Brasil

http://lattes.cnpq.br/1285735936056598

http://orcid.org/00000-0002-2517-6147

anaphaskel@gmail.com

Luiz Felipe Ferreira (iD

Universidade Federal de Santa Catarina, Brasil

http://lattes.cnpq.br/4585384535802013

http://orcid.org/0000-0002-6162-8905

luizff67@gmail.com
Referencing this:

HASKEL, A. P.; FERREIRA, L. F.. Controles internos e a sua eficiência ou ineficiência no processo tributário aplicado ao setor varejista de cosméticos e perfumaria: um estudo teórico empírico. Revista Brasileira de Administração Científica, v.11, n.4, p.219-226, 2020. DOI: http://doi.org/10.6008/CBPC2179-684X.2020.004.0017 
Controles internos e a sua eficiência ou ineficiência no processo tributário aplicado ao setor varejista de cosméticos e perfumaria: um estudo

\section{INTRODUÇÃO}

É notória a existência de uma alta carga tributária no Brasil sendo assim indiscutíveis como os tributos existentes oneram os nossos produtos e serviços. Além disso, a burocracia que há em relação à aplicação da legislação existente em todas as esferas, seja federal, estadual e municipal, remete ao cenário oneroso e burocrático quando o tema é tributo. Pois, além da carga tributária existente, existem inúmeras legislações com diferenciais de alíquota e até mesmo alguns benefícios, aplicáveis a alguns setores/produtos, com o objetivo de desonerar essa carga e alavancar a economia. Entretanto para que haja a correta aplicação de tais benefícios, faz-se necessário alguns controles internos para identificação do setor e dos produtos que poderão usufruir de possíveis reduções tributárias.

Diante destas iniciais circunstâncias se faz necessário um controle adequado do processo comercial de uma empresa, não apenas dos produtos, como 'compra e venda', controle de 'estoque' e 'caixa', mas da atualização contínua na legislação. Isso poderia ser considerado uma circunstância óbvia a partir da lente de qualquer profissional tributário, entretanto os controles existentes permitem uma apuração tributaria adequada?.

É preconizado que o sistema de controle de gestão deva direcionar o comportamento dos administradores para o cumprimento dos objetivos estipulados pelos acionistas/proprietários e assegurar que deles não se afastem "por má-fé, negligência, cupidez ou simples incompetência” (HELLWIG, 2000). Portanto, partindo desse pressuposto, o caminho é longo para alcançar uma eficiência mínima necessária.

Dessa forma, o objetivo deste estudo é demonstrar se a falta de controles internos influencia na tributação inadequada, devido a não identificar possíveis benefícios que poderiam ser aplicados em determinado setor e produto. De acordo com isso, essas são as seguistes questões específicas deste trabalho: A tributação de uma empresa poderá sofrer alterações pela ineficiência dos controles internos? Os controles existentes são suficientes para identificação e apuração correta de tributos pelo profissional contábil?'

Existem inúmeros benefícios possíveis na legislação brasileira, como, também, vários tributos e muitas formas tributárias existentes como redução a zero, substituição tributária, monofásico, sem incidência (...) este estudo não tem o objetivo de avaliar a utilização de todos os benefícios, apenas de fazer um estudo empírico da validade dos controles internos em determinado setor, que é o de cosméticos e perfumaria, na revenda a varejo. Os tributos estudados serão as contribuições sociais o PIS/Pasep e a Cofins. A região alvo da pesquisa é a grande Florianópolis. A lente deste estudo é a revenda de determinados produtos, bem como se essas informações estão disponíveis e são controladas pelos profissionais contábeis.

Este estudo teórico empírico de identificação dos controles internos no reconhecimento dos benefícios tributários, apesar da alta carga da tributação que há no País, justifica-se pela importância de identificar se essas contribuições estão de acordo com a legislação ou se há inadequação devido à falta dos aludidos controles.

Dessa forma, este artigo tem por objetivo buscar respostas para a questão levantada, fundamentando-se: (i) no desenvolvimento da literatura conceitual sobre os controles internos; (ii) no 
Controles internos e a sua eficiência ou ineficiência no processo tributário aplicado ao setor varejista de cosméticos e perfumaria: um estudo

conceito de tributação e redução tributária de duas contribuições específicas o PIS/Pasep e a Cofins no setor de cosméticos e perfumaria - varejista conhecida como tributação monofásica; (iii) na demonstração do possível impacto que há entre a falta de controle e a tributação desnecessária dessas duas contribuições (benefícios específicos tributários).

\section{REVISÃO TEÓRICA}

\section{Controles Internos}

Imoniana et al. (2004) definem controle como a espinha dorsal do exercício de gestão: "quando seus modelos são conscientemente desenhados e implementados em um ambiente harmonioso ele tende a auxiliar os objetivos desejados".

De acordo com figueiredo et al. (2004), controle é um sistema de feedback que possibilita o desempenho ser comparado com os objetivos planejados e é necessário para a realização do planejamento de curto e longo prazo. Esse controle deve possibilitar uma visão clara dos acontecimentos efetivos, executando medições desses acontecimentos e apontando as distorções. Lembrando que os sistemas de controle de gestão devem direcionar o comportamento dos administradores para o cumprimento dos objetivos estipulados pelos acionistas/proprietários e assegurar que deles não se afastem "por má-fé, negligência, cupidez ou simples incompetência" (HELLWIG, 2000).

Conforme Martin et al. (2004), ainda hoje, na maior parte das empresas, os administradores, que já têm o poder de decidir e fazer têm, também, paradoxalmente, o poder de informar sobre o que fazem, tanto para o Conselho como para os proprietários/acionistas. Como são eles que aplicam os recursos investidos na empresa e também os que produzem as informações relacionadas sobre suas decisões, podem ser formadas substanciais assimetrias de informação favorecendo os administradores, entre os quais, infelizmente, estão aqueles que foram antes tipificados por Hellwig (2000).

Conforme determina Gattringer et al. (2018), a implantação e a manutenção dos controles internos nas organizações estão amplamente difundidas na teoria. Os controles internos se referem a todos os instrumentos da organização destinados à vigilância, fiscalização e verificação, que permitam prever, observar, dirigir ou governar seus atos que produzem reflexos patrimoniais. Envolvem todas as atividades e rotinas, de natureza contábil e administrativa, fixando padrões de comportamento com o intuito de estabelecer o entendimento por parte dos colaboradores, de acordo com Reske Filho (2005).

Com o objetivo de implementar a estrutura do risco, os conceitos sobre os controles corroboram com a análise pré-determinada na qual Imoniana et al. (2004) o definem como a espinha dorsal do exercício de gestão: "quando seus modelos são conscientemente desenhados e implementados em um ambiente harmonioso ele tende a auxiliar os objetivos desejados".

Gattringer et al. (2018) colocam que o conceito de controle interno mais difundido é o enunciado para o ramo contábil pelo American Institute of Certified Public Accountants - AICPA, em 1949, corroborado por autores como Almeida (2003), Cruz et al. (2006), e Attie (2011), definindo-o como o plano de organização 
Controles internos e a sua eficiência ou ineficiência no processo tributário aplicado ao setor varejista de cosméticos e perfumaria: um estudo

e todos os métodos e medidas adotadas na empresa para: salvaguardar seu patrimônio; verificar a exatidão e fidelidade dos dados contábeis; desenvolver a eficiência nas operações; e estimular o seguimento das políticas executivas prescritas (CASTRO, 2008).

\section{Tributo}

O sistema tributário nacional é regido pelo disposto na Emenda Constitucional n. 18 , de 10 de dezembro de 1965, em leis complementares, em resoluções do Senado Federal e nos limites das respectivas competências, em leis federais, nas Constituições e em leis estaduais e municipais.

Considera-se tributo, conforme o Código Tributário Nacional, toda prestação pecuniária compulsória, em moeda ou cujo valor nela se possa exprimir, que não constitua sanção de ato ilícito, instituída em lei e cobrada mediante atividade administrativa plenamente vinculada. São classificados como tributos: impostos, taxas e contribuições de melhoria. Estes tributos são segregados por tributos federais, estaduais e municipais.

\section{Contribuições Sociais: PIS/Pasep e Cofins}

O Programa de Integração Social (PIS) e o Programa de Formação do Patrimônio do Servidor Público (PASEP), mais conhecidos como PIS/PASEP, são contribuições sociais de natureza tributária, devidas pelas pessoas jurídicas, com objetivo de financiar o pagamento do seguro-desemprego, abono e participação na receita dos órgãos e entidades para os trabalhadores públicos e privados.

A Contribuição para o Financiamento da Seguridade Social (COFINS) é uma contribuição federal, de natureza tributária, incidente sobre a receita bruta das empresas em geral, destinada também a financiar a seguridade social.

O Regime Cumulativo para apuração do PIS/Pasep e da Cofins para todas as empresas optantes pelo regime do Lucro Presumido e para empresas enquadradas no Lucro Real (BRASIL, 1998).

Posteriormente, foi publicada a sistemática não cumulativa para fins de cálculo do PIS/Pasep (BRASIL, 2002). No ano seguinte, a sistemática não cumulativa se estendeu para o cálculo da Cofins para todas as empresas enquadradas no Lucro Real (BRASIL, 2003).

Via de regra, cada setor aplica-se a tributação conforme o seu enquadramento tributário e setor específico, entretanto há tributações diferenciadas, como a tributação monofásica, onde a tributação diferenciada, também conhecida por incidência monofásica ou concentrada, abrange um grupo de produtos que estão sujeitos à aplicação de alíquotas específicas diferentes das usuais do regime cumulativo e do regime não cumulativo (BRASIL, 2019).

A diferença dessa sistemática não se limita, no entanto, às alíquotas. A tributação diferenciada se assemelha muito à substituição tributária, uma vez que o ônus tributário de toda a cadeia de comercialização do produto recai sobre fabricante ou importador, enquanto os demais contribuintes da cadeia de comercialização (atacadista e o varejista) tributam as receitas auferidas nas vendas dos mesmos produtos 
Controles internos e a sua eficiência ou ineficiência no processo tributário aplicado ao setor varejista de cosméticos e perfumaria: um estudo

com alíquota zero (BRASIL, 2000).

Os produtos que estão nessa classificação, via de regra, são os produtos farmacêuticos, cosméticos, combustíveis, autopeças (BRASIL, 2019).

\section{METODOLOGIA}

\section{Método de pesquisa e análise dos dados}

Os dados foram coletados por meio de um questionário de pesquisa, respondido presencialmente pelo gerente/caixa/responsável da loja quando da coleta de dados no dia 11 a 15 de novembro de 2018, estruturado de forma vertical. Os produtos investigados são da linha de cosméticos que estão disponibilizados no quadro 1.

Quadro 1: Produtos fontes de pesquisa.

Produtos de Perfumaria, de Toucador ou de Higiene Pessoal.

\begin{tabular}{|l|}
\hline 1- Posições: \\
\hline 33.03, 33.04, 33.05 e 33.07; \\
\hline 2- Códigos: \\
\hline 3401.11.90 (exceto 3401.11.90 Ex 01), \\
\hline 3401.20.10 e 96.03.21.00. \\
\hline
\end{tabular}

Em relação às lojas escolhidas foi aplicada uma filtragem nas lojas a varejo do Shopping da região de Florianópolis. Inicialmente, para fins de amostra, foram identificadas as lojas de perfumes/cosméticos. A busca foi realizada via site do próprio Shopping.

Quadro 2: Lojas de perfumes e cosméticos do Shopping.

\begin{tabular}{|l|l|}
\hline Setor & Quantidade de lojas \\
\hline Cosméticos, maquiagens e afins & 2 \\
\hline Perfumaria e Cosméticos & 5 \\
\hline Cabeleireiros & 1 \\
\hline Cabeleireiros e Barbearia & 1 \\
\hline Total & $\mathbf{9}$ \\
\hline
\end{tabular}

A pesquisa direcionou-se especificamente para as lojas de perfumes e cosméticos, as empresas de departamento, como farmácias (potenciais vendedoras de perfumes e cosméticos), não fizeram parte da pesquisa. Portanto, com o intuito e verificar as condições de controle especificamente nas lojas de perfumes e cosméticos, o instrumento de pesquisa foi aplicado nas lojas relacionadas no quadro 2 .

Como a pesquisa foi aplicada presencialmente e em dia específico, houve o aceite, ou não, das lojas arroladas como participantes do estudo.

Quadro 3: Percentual de aderência à pesquisa.

\begin{tabular}{|l|l|l|l|l|l|}
\hline $\begin{array}{l}\text { Quantidade de lojas } \\
\text { pesquisadas }\end{array}$ & $\begin{array}{l}\text { Quantas lojas } \\
\text { aceitam participar }\end{array}$ & $\begin{array}{l}\text { Quantas lojas negaram a } \\
\text { participação }\end{array}$ & $\begin{array}{l}\text { Motivos da não } \\
\text { participação }\end{array}$ & $\begin{array}{l}\text { Percentual de } \\
\text { aderência }\end{array}$ \\
\hline 9 & 7 & 2 & $\begin{array}{l}\text { Fluxo de pessoas/não } \\
\text { fornecia informações }\end{array}$ & $77,77 \%$ \\
\hline
\end{tabular}

Apesar de não existir uma grande quantidade de empresas envolvidas, o percentual de aderência foi considerado satisfatório para a finalidade do trabalho. No próximo quadro 4 , estão destacados dados relevantes sobre as empresas de perfumes e cosméticos pesquisadas. 
Controles internos e a sua eficiência ou ineficiência no processo tributário aplicado ao setor varejista de cosméticos e perfumaria: um estudo

Quadro 4: Dados apurados nas lojas pesquisadas.

\begin{tabular}{|c|c|c|}
\hline Perguntas & Sim & Não \\
\hline Franquia & 5 & 2 \\
\hline Apenas varejista & 4 & 3 \\
\hline Funcionário responsável pelo estoque & 4 & 3 \\
\hline Vendem produtos monofásicos & 7 & 0 \\
\hline Documento enviado para o contador/administração é apenas a soma das vendas & 5 & 2 \\
\hline Enviam algum documento com a listagem dos produtos segregados & 2 & 5 \\
\hline
\end{tabular}

Como trata-se de uma pesquisa vertical, o intuito não é analisar todos os procedimentos de controle das empresas em questão, mas levantar hipóteses e indicadores em relação as falhas de um processo, onde está falha compromete o reconhecimento tributário adequado. A partir destas informações, observa-se a possibilidade que apenas duas empresas possuem um controle eficiente dos seus estoques. Considerando que este controle é primordial para uma eficiência no processo de controle dos produtos, consequentemente do controle tributário. Considerando essa falta de controle interno pressupõe-se que possivelmente apenas $28,6 \%$ das empresas teriam condições de aplicar uma correta tributação e que $71,4 \%$ das empresas em pauta não possuem um controle adequado sobre as suas vendas, o que possivelmente acarretaria tributação desnecessária. Sem controle adequado sobre as vendas, não há como haver a segregação dos produtos vendidos, portanto não há como o profissional contábil proceder ao desmembramento dos produtos, o que poderia acarretar a redução do valor dos tributos em estudo (PIS/Pasep e a COFINS). Dentre as empresas constatou-se que as franquias possuem controles mais precários, isso pode ser devido à estrutura empresarial inadequada.

\section{CONCLUSÕES}

A legislação tributária está em constante mudança, havendo a publicação de alterações de frequência praticamente diária. Como há muitas leis relativas ao tema, isso dificulta que haja uma atualização com a velocidade necessária para que atos inapropriados não sejam realizados em termos de verificação de montante de tributos a serem pagos.

No Brasil a carga tributária das empresas é elevada, mas, por vezes, por causa de questões administrativas e contábeis da própria empresa pode haver incidência de tributação mais do que a necessária. Assim, infere-se que a falta de controle na empresa é um dos fatores que pode acarretar ineficiência tributária. A coleta de dados deste estudo mostrou que $71,4 \%$ das empresas não apresentaram controles básicos que possam identificar tributos passíveis de sofrerem reduções tributárias. Considerando o estudo em pauta, sobre a cobrança adequada de PIS/PASEP e COFINS, há possibilidade de haver isenção de suas cobranças, portanto as empresas sem controle interno eficaz estão correndo esse risco tributário.

Este trabalho é um estudo-piloto com objetivo de futuramente investigar-se outros fatores que indiquem como as informações são repassadas para a contabilidade e como os profissionais lidam com a escassez de informações.

Esta coleta de dados preliminar foi realizada com limitações, uma delas foi a pesquisa ter sido feita em lojas de um único shopping. Outra limitação desta pesquisa é que não foi apurado como os profissionais 
da área contábil recebem as informações que necessitam. Além disso, não foi pesquisado sobre o tipo de controle de estoque utilizado, embora haja lojas que informaram que não o utilizam.

Essas limitações tendem a ser solucionadas em estudos futuros pela aplicação de questionário em lojas da grande Florianópolis para que haja resultados mais confiáveis. Também será elaborado instrumento de pesquisa que investigue sobre como os dados chegam até o profissional contábil e se ele possui conhecimento sobre os tributos passíveis de redução tributária. Justifica-se a importância de o profissional receber as informações adequadas, porque a legislação é vasta e complexa, apresentando várias lacunas. Devido a isso a tarefa de levantar o montante devido não é fácil e é também dificultada se não existe controle efetivo.

Secundariamente, por meio dos dados coletados, foi observado que as empresas que não são franquias apresentam melhor estrutura e consequentemente tem a possibilidade de aplicar de forma mais adequada a tributação sobre seus produtos.

Ressalta-se que este estudo é 'a ponta de um iceberg', pois a tributação não é composta apenas de PIS/PASEP e COFINS, de um único benefício, como também há vários setores na empresa, cada um com a sua peculiaridade. $\mathrm{O}$ foco nesses tributos é apenas para demonstrar que a falta de controle pode ser causa de arrecadação desnecessária. De forma geral, conclui-se que a apuração dos tributos da empresa pode ser ineficiente se os controles internos não são eficazes, o que pode acarretar grandes prejuízos a ela.

\section{REFERÊNCIAS}

ALMEIDA, M. C.. Auditoria: um curso moderno e completo. 6 ed. São Paulo: Atlas, 2003.

ATTIE, W.. Auditoria interna. 6 ed. São Paulo: Atlas, 2011.

BRASIL. Decreto-Lei n. 9.295, de 27 de maio de 1946. Cria o Conselho Federal de Contabilidade, define as atribuições do Contador e do Guarda-livros, e dá outras providências; Rio de Janeiro, RJ, maio 1946.

BRASIL. Lei n. 9.718, de 27 de novembro de 1998. Altera a Legislação Tributária Federal. Brasília: DOU, 1998.

BRASIL. Lei $\mathbf{n} . \mathbf{1 0 . 1 4 7}$, de 21 de dezembro de 2000. Dispõe sobre a incidência da contribuição para os Programas de Integração Social e de Formação do Patrimônio do Servidor Público - PIS/Pasep, e da Contribuição para o Financiamento da Seguridade Social - Cofins, nas operações de venda dos produtos que especifica. Brasília: DOU, 2000.

BRASIL. Lei n. 10.485, de 03 de julho de 2002. Dispõe sobre a incidência das contribuições para os Programas de Integração Social e de Formação do Patrimônio do Servidor Público (PIS/Pasep) e da Contribuição para o Financiamento da Seguridade Social (Cofins), nas hipóteses que menciona, e dá outras providências. Brasília: DOU, 2002.

BRASIL. Lei n. 10.833, de 29 de dezembro de 2003. Altera a Legislação Tributária Federal e dá outras providências. Brasília: DOU, 2003.
BRASIL. Decreto n. 4.524, de 17 de dezembro de 2002. Regulamenta a Contribuição para o PIS/Pasep e a Cofins devidas pelas pessoas jurídicas em geral. Brasília: DOU, 2002.

BRASIL. Instrução Normativa n. 1.911, de 11 de outubro de 2019. Regulamenta a apuração, a cobrança, a fiscalização, a arrecadação e a administração da Contribuição para o PIS/Pasep, da Cofins, da Contribuição para o PIS/PasepImportação e da Cofins-Importação. Brasília: DOU, 2019.

CASTRO, D. P.. Auditoria e controle interno na administração pública: evolução do controle interno no Brasil, do Código de Contabilidade de 1922 até a criação da CGU em 2003. São Paulo: Atlas, 2008.

CRUZ, F.; GLOCK, J. O.. Controle interno nos municípios. São Paulo: Atlas, 2006.

FIGUEIREDO, A.; CAGGIANO, P. C.. Controladoria. Teoria e Prática. 3 ed. São Paulo: Atlas, 2004.

GATTRINGER, J. L.; MARINHO, S. V.. O Uso do Modelo cOSO na Administração Pública: Um Estudo nos Municípios Catarinenses. Enfoque Reflexão Contábil, v.39, n.1, p.75-95, 2020.

HELLWIG, M.. On the economics and politics of corporate finance and corporate control, in corporate governance. Cambridge: Cambridge University Press, 2000. 
Controles internos e a sua eficiência ou ineficiência no processo tributário aplicado ao setor varejista de cosméticos e perfumaria: um estudo teórico empírico

IMONIANA, J. O.; NOHARA, J. J.. Cognição da estrutura de controle interno: uma pesquisa exploratória. BASE: Revista da Administração e Contabilidade da Unisinos, v.2, n.1, p.37-46, 2005.

MARTIN, N. C.; SANTOS, L. R.; DIAS FILHO, J. M.. Governança empresarial, riscos e controles internos: a emergência de um novo modelo de controladoria. Rev. Contab. Finanç., São Paulo, v.15, n.34, 2004.

RESKE FILHO, A.; JACQUES, E. A.; MARIAN, P. D.. O controle interno como ferramenta para o sucesso empresarial. Revista Eletrônica de Contabilidade, v.1, n.3, p.107-118, 2005.

A CBPC - Companhia Brasileira de Produção Científica (CNPJ: 11.221.422/0001-03) detém os direitos materiais desta publicação. Os direitos referem-se à publicação do trabalho em qualquer parte do mundo, incluindo os direitos às renovações, expansões e disseminações da contribuição, bem como outros direitos subsidiários. Todos os trabalhos publicados eletronicamente poderão posteriormente ser publicados em coletâneas impressas sob coordenação da Sustenere Publishing, da Companhia Brasileira de Produção Científica e seus parceiros autorizados. Os (as) autores (as) preservam os direitos autorais, mas não têm permissão para a publicação da contribuição em outro meio, impresso ou digital, em português ou em tradução. 